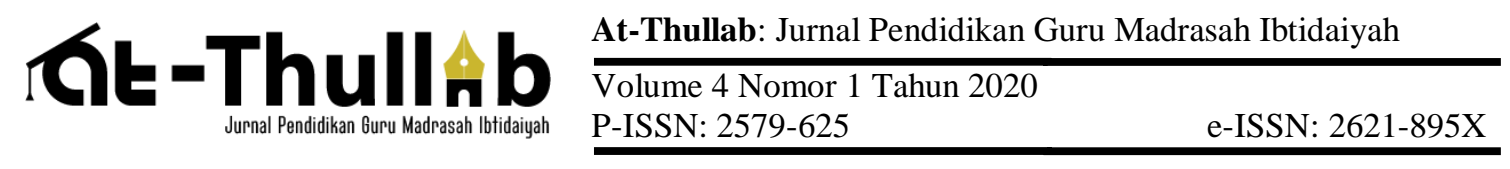

\title{
ANALISIS KREATIVITAS SISWA KELAS 3 DALAM MENGELOLA SAMPAH PLASTIK PADA PELAJARAN PLH DI SD NEGERI 1 WONOKROMO KECAMATAN GONDANG
}

\author{
Dessy Ayu Permata Hadi ${ }^{1}$, Rohmatus Syafi'ah ${ }^{2}$ \\ ${ }^{1}$ STKIP PGRI Tulungagung, ${ }^{2}$ STKIP PGRI Tulungagung \\ e-mail: ${ }^{1}$ ayupermatadessy@ gmail.com,${ }^{2}$ syafiahzainul@ gmail.com,
}

\begin{abstract}
The Creativity is very needed to manage plastic waste become something new and can be re-used, because in Wonokromo district at Tulungagung was still many plastics waste that wasted and just fired, finally can be caused air-polution. The purpose of this research to know there is any creativity from students to manage plastic waste to be creative product that have a new value. Creative product that resulted from students at class 3 at SDN 1 Wonokromo valued with three criterias, it is: newness, fission, and detailed. Data collection methods that used is observation, interview, and documentation. The instrument that used is observation with ratting scale in create a data, and also use data of interview and documentation to support a data that a result of researcher. From this analysis data that result show that there is any creativity of students in class 3 at SDN 1 Wonokromo is very good because from fourteen students only one student that have a good criteria. The higher presentation is $94 \%$ and the lower is $68 \%$.
\end{abstract}

Keywords: creativity, creative products, plastic waste

\section{A. Pendahuluan}

PLH (Pendidikan Lingkungan Hidup atau environmental education) merupakan suatu pendidikan yang berbentuk proses yang berupaya untuk membangun manusia agar sadar dan peduli terhadap lingkungan serta segala masalah yang berkaitan dengannya (Budiono, 2017). PLH adalah salah satu pelajaran yang penting untuk diajarkan di sekolah karena dengan adanya mata pelajaran PLH siswa diharapkan memiliki kepedulian, menghargai dan menjaga lingkungan sekitarnya. PLH diajarkan mulai jenjang SD sampai dengan perguruan tinggi. Hal ini menunjukkan bahwa PLH merupakan salah satu mata pelajaran yang sangat penting oleh karena itu, sejak SD siswa seharusnya sudah diajarkan PLH karena dengan pendidikan ini mereka akan menegetahui apa yang harus dilakukan untuk mengurangi kerusakan lingkungan. Contohnya dengan mengurangi banyaknya sampah plastik yang saat ini sudah sangat menumpuk.

Mata pelajaran PLH di SD merupakan mata pelajaran Muatan Lokal (MULOK). Salah satu materi yang diajarkan dalam pelajaran PLH adalah mengenai pengeloaan sampah. Upaya mengurangi penumpukan sampah plastik agar sampah tersebut dapat 
dimanfaatkan kembali dan memiliki nilai ekonomis maka diperlukan kreativitas untuk mengolah sampah plastik tersebut.

Kemampuan seseorang dalam menciptakan gagasan, prosedur, atau produk dinamakan kreativitas (Sudarma, 2013) Konsep kreatif akan terpenuhi jika ada karya atau produk yang nyata. Karya nyata yang dimaksud adalah berupa produk kreatif yang akan dibuat oleh siswa. Produk kreatif tersebut dapat dilihat dari beberapa indikator yaitu kebaruan (novelty), pemecahan (resolution), keterperincian (elaboration) dan sintesis, Besemer dan Treffirger (dalam Munandar, 2009:41).

Berdasarkan hasil observasi yang telah dilakukan di SD Negeri 1 Wonokromo, permasalahan yang ada saat ini adalah kurangnya inovasi dalam pengelolaan sampah plastik di SD Negeri I Wonokromo serta banyaknya sampah plastik yang menumpuk. Hal tersebut dibuktikan dengan sedikitnya jenis kerajinan tangan siswa dari sampah plastik, dalam pengelolaan sampah plastik siswa masih dibatasi dalam penggunaan bahan baku sampah plastik yaitu hanya menggunakan gelas air mineral saja, melalui penelitian ini peneliti ingin menganalis sejauh mana kreativitas siswa dalam mengelola sampah plastik, dimana siswa dibebaskan untuk memlilih jenis sampah plastik apa yang akan digunakan dan diolah sesuai dengan kreativitas mereka masing masing. Untuk mengetahui sejauh mana kreativitas siswa maka judul penelitian yang diambil adalah "Analisis Kreativitas Siswa Kelas 3 dalam Mengelola Sampah Plastik pada pelajaran PLH di SD Negeri 1 Wonokromo Kecamatan Gondang."

\section{B. Metode}

Pendekatan penelitian yang digunakan dalam penelitian ini adalah deskriptif kualitatif. Penelitian kualitatif adalah suatu penelitian yang menggunakan cara penyajian data yang berupa kata-kata. Penelitian deskriptif merupakan suatu penelitian yang bermaksud untuk memecahkan masalah yang ada sekarang berdasarkan data-data yang telah diperoleh. Jenis penelitian ini merupakan jenis penelitian deskriptif yang memaparkan pemecahan masalah dengan data-data yang ada sekarang. (Moleong, 2017: 11) deskriptif adalah data yang berupa kata-kata, gambar, dan bukan angka-angka.

Prosedur penelitian kualitatif yang dilakukan melalui beberapa tahapan. (Moleong, 2017: 127) mengatakan bahwa dalam melakukan penelitian kualitatif, peneliti melakukan beberapa tahapan yaitu pelakasanaan penelitian ada 4 tahap yaitu : tahap sebelum ke lapangan, tahap pekerjaan lapangan, tahap analisis data, tahap penulisan laporan.

Subjek utama penelitian ini adalah siswa kelas 3 SD Negeri 1 Wonokromo. Sekolah ini terletak di Desa Wonokromo Kecamatan Gondang Kabupaten Tulungagung. Penelitian ini dilaksanakan pada semester genap dengan alokasi waktu mulai bulan Maret hingga Mei. 
Instrumen penelitian yang digunakan oleh peneliti berupa lembar observasi dan lembar wawancara. Adapun kisi-kisi lembar observasi dan lembar wawancara yang peneliti gunakan adalah sebagai berikut :

Tabel 1. Kisi-Kisi Pedoman Observasi Kreativitas Siswa Kelas 3dalam Mengelola Sampah Plastik

\begin{tabular}{|l|l|l|l|}
\hline No. & INDIKATOR & ASPEK & DESKRIPSI \\
\hline 1. & Kebaruan (novelty) & Barang Baru & $\begin{array}{l}\text { Siswa mampu mengolah sampah plastik } \\
\text { menjadi barang yang baru. }\end{array}$ \\
\cline { 2 - 4 } & Keaslian & $\begin{array}{l}\text { Siswa mampu mengolah sampah plastik } \\
\text { berasal dari ide/pemikirannya sendiri. }\end{array}$ \\
\hline 2. & $\begin{array}{l}\text { Pemecahan } \\
\text { (resolution) }\end{array}$ & Berguna & $\begin{array}{l}\text { Siswa mampu membuat produk dari } \\
\text { sampah plastik yang memiliki banyak } \\
\text { nilai guna. }\end{array}$ \\
\hline 3. & $\begin{array}{l}\text { Keterperincian } \\
\text { (elaboration) }\end{array}$ & Kompleks & $\begin{array}{l}\text { siswa mampu membuat detail produk } \\
\text { dari sampah plastik (potongan, lipatan, } \\
\text { dan warna) }\end{array}$ \\
\hline
\end{tabular}

Sumber : Adaptasi Model dari Bessemer dan Treffiger (dalam Munandar, 2009)

Tabel 2. Kisi-Kisi Wawancara Kreativitas Siswa Kelas 3 dalam Mengelola Sampah Plastik

\begin{tabular}{|l|l|l|}
\hline INDIKATOR & ASPEK & PERTANYAAN \\
\hline Kebaruan & Barang Baru & $\begin{array}{l}\text { Apakah dalam mengelola sampah } \\
\text { plastik kamu membuat menjadi } \\
\text { barang yang baru ? }\end{array}$ \\
\cline { 2 - 3 } & Keaslian & $\begin{array}{l}\text { Apakan dalam mengelola sampah } \\
\text { plastik berasal dari pemikiranmu } \\
\text { atau idemu sendiri? }\end{array}$ \\
\hline Pemecahan & Berguna & $\begin{array}{l}\text { Apakah fungsi dari produk yang } \\
\text { kamu buat? }\end{array}$ \\
\hline Keterperincian & Kompleks & $\begin{array}{l}\text { Bagaimana cara kamu dalam } \\
\text { membuat produk dari sampah } \\
\text { plastik? }\end{array}$ \\
\hline
\end{tabular}

Sumber : Adaptasi Model dari Bessemer dan Treffiger (dalam Munandar, 2009)

Teknik pengumpulan data yang digunakan peneliti adalah dengan menggunakan teknik observasi, wawancara, serta dokumentasi. Dalam teknik observasi cara pengukurannya menggunakan rating scale dengan rentang angka 1-4 dimana 1 merupakan skor terendah dan 4 merupakan skor tertinggi, setelah didapat skor akhir maka prosentase dapat dihitung dengan rumus yang diadaptasi dari (Sudijono, 2009): 


$$
\text { Prosentase }(\%)=\frac{\text { Jumlah skor yang diperoleh }}{\text { Jumlah skor maksimal }} \times 100 \%
$$

Tabel 3. Skala Prosentase

\begin{tabular}{|c|c|}
\hline$\geq 75 \%$ & Sangat Baik \\
\hline $51 \%-74 \%$ & Baik \\
\hline $24 \%-50 \%$ & Cukup Baik \\
\hline$\leq 25 \%$ & Perlu Revisi \\
\hline
\end{tabular}

(Sugiyono, 2016)

Teknik wawancara dan dokumentasi merupakan teknik pendukung observasi untuk memperkuat hasil observasi. Saat melakukan wawancara peneliti menggunakan alat bantu lembar wawancara, pedoman wawancara, serta alat perekam agar kegiatan wawancara berjalan dengan lancar. Teknik dokumentasi ini menggunakan alat bantu kamera untuk mengabadikan proses siswa dalam mengelola sampah plastik.

Teknik analisis data peneliti menggunakan reduksi data, penyajian data, dan verifikasi data. Dalam mereduksi data meneliti memilah-milah data mana saja yang perlu digunakan, dalam penyajian data peneliti menyajikan data dari data-data yang telah dipilih setelah mereduksi data, dan yang terakhir adalah verifikasi data peneliti membuat kesimpulan awal yang masih bersifat sementara, dan akan berubah bila tidak ditemukan bukti-bukti yang kuat yang mendukung pada tahap pengumpulan data berikutnya.

Pengecekan keabsahan data peneliti menggunakan: 1) peningkatan ketekunan yaitu peneliti dapat memberika deskripsi yang akurat tentang apa yang sedang diteliti. 2) menggunakan bahan referensi yaitu dalam penelitian sangat dibutuhkan dokumentasi untuk mendapatkan foto atau dokumen yang autentik agar data lebih dapat dipercaya. 3) triangulasi, peneliti menggunakan triangulasi teknik dan teknik yang akan digunakan adalah observasi, wawancara, dan dokumentasi

\section{Hasil dan Pembahasan}

Hasil penelitian ini mencakup tentang bagaimana kreativitas siswa kelas III dalam mengelola sampah plastik di SD Negeri 1 Wonokromo Kecamatan Gondang. Hasil dari penelitian ini dapat dilihat di tabel rekapitulasi di bawah ini : 
Dessy Ayu Permata Hadi, Rohmatus Syafi'ah

Tabel 4. Hasil Rekapitulasi Observasi Kreativitas Siswa dalam Mengelola Sampah Plastik

\begin{tabular}{|c|c|c|c|c|c|c|c|c|}
\hline \multirow{3}{*}{ No. } & \multirow{3}{*}{ Nama } & \multicolumn{4}{|c|}{ Indikator } & \multirow{3}{*}{ Total } & \multirow{3}{*}{$\begin{array}{c}\text { Prosentase } \\
(\%)\end{array}$} & \multirow{3}{*}{ Ket. } \\
\hline & & \multicolumn{2}{|c|}{ Kebaruan } & \multirow{2}{*}{$\frac{\text { Pemecahan }}{\text { Berguna }}$} & \multirow{2}{*}{\begin{tabular}{|c|} 
Keterperincian \\
Kompleks
\end{tabular}} & & & \\
\hline & & $\begin{array}{c}\text { Bahan } \\
\text { Baru }\end{array}$ & Keaslian & & & & & \\
\hline 1 & H.T.C & 4 & 3 & 3 & 4 & 14 & $87 \%$ & $\begin{array}{l}\text { Sangat } \\
\text { Baik }\end{array}$ \\
\hline 2 & A.J.A.F & 4 & 3 & 4 & 4 & 15 & $94 \%$ & $\begin{array}{l}\text { Sangat } \\
\text { Baik }\end{array}$ \\
\hline 3 & A.A.P & 4 & 3 & 4 & 3 & 14 & $87 \%$ & $\begin{array}{l}\text { Sangat } \\
\text { Baik }\end{array}$ \\
\hline 4 & A.Z.A.M & 4 & 2 & 3 & 4 & 13 & $81 \%$ & $\begin{array}{l}\text { Sangat } \\
\text { Baik }\end{array}$ \\
\hline 5 & C.D.J & 4 & 3 & 4 & 4 & 15 & $94 \%$ & $\begin{array}{l}\text { Sangat } \\
\text { Baik }\end{array}$ \\
\hline 6 & M.F & 4 & 3 & 4 & 3 & 14 & $87 \%$ & $\begin{array}{l}\text { Sangat } \\
\text { Baik }\end{array}$ \\
\hline 7 & M.A.S & 4 & 4 & 2 & 3 & 13 & $81 \%$ & $\begin{array}{l}\text { Sangat } \\
\text { Baik }\end{array}$ \\
\hline 8 & M.R.A & 4 & 3 & 4 & 3 & 14 & $87 \%$ & $\begin{array}{l}\text { Sangat } \\
\text { Baik }\end{array}$ \\
\hline 9 & N.V & 4 & 3 & 4 & 3 & 14 & $87 \%$ & $\begin{array}{l}\text { Sangat } \\
\text { Baik }\end{array}$ \\
\hline 10 & N.B & 4 & 3 & 3 & 4 & 14 & $87 \%$ & $\begin{array}{l}\text { Sangat } \\
\text { Baik }\end{array}$ \\
\hline 11 & R.R & 4 & 4 & 3 & 4 & 15 & $94 \%$ & $\begin{array}{l}\text { Sangat } \\
\text { Baik }\end{array}$ \\
\hline 12 & R.R & 4 & 4 & 3 & 3 & 14 & $87 \%$ & $\begin{array}{l}\text { Sangat } \\
\text { Baik }\end{array}$ \\
\hline 13 & S.P.P & 4 & 2 & 2 & 3 & 11 & $68 \%$ & Baik \\
\hline 14 & Y.I & 4 & 3 & 3 & 3 & 13 & $81 \%$ & $\begin{array}{l}\text { Sangat } \\
\text { Baik }\end{array}$ \\
\hline $\begin{array}{l}\text { Tota } \\
\text { Kese }\end{array}$ & luruhan & 56 & 43 & 46 & 48 & 193 & & \\
\hline
\end{tabular}




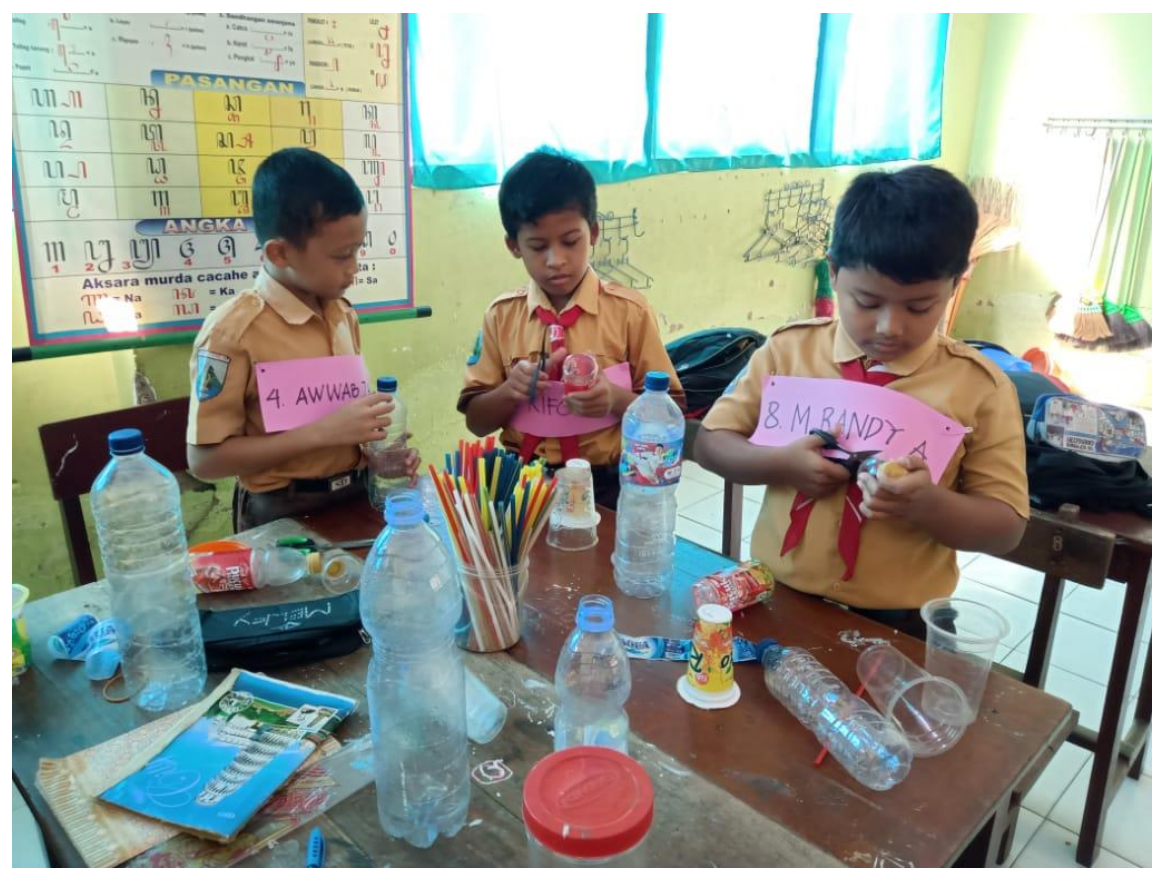

Gambar 1. Proses pengelolaan sampah plastic

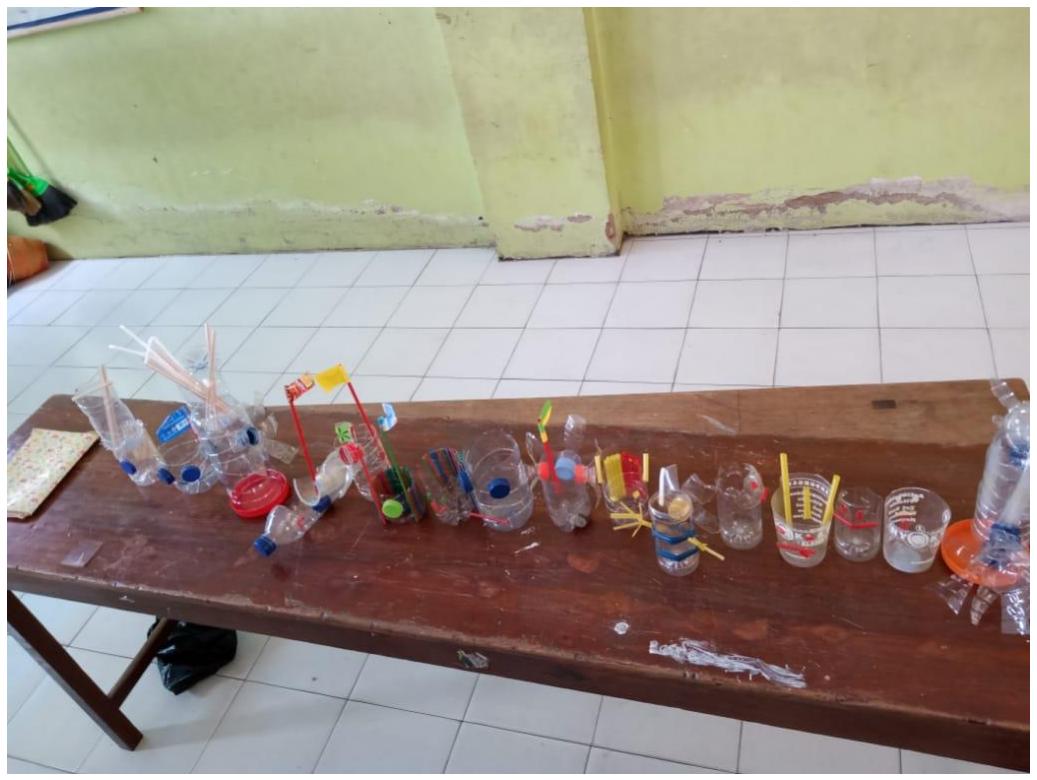

Gambar 2. Produk Kreatif yang belum diwarnai 


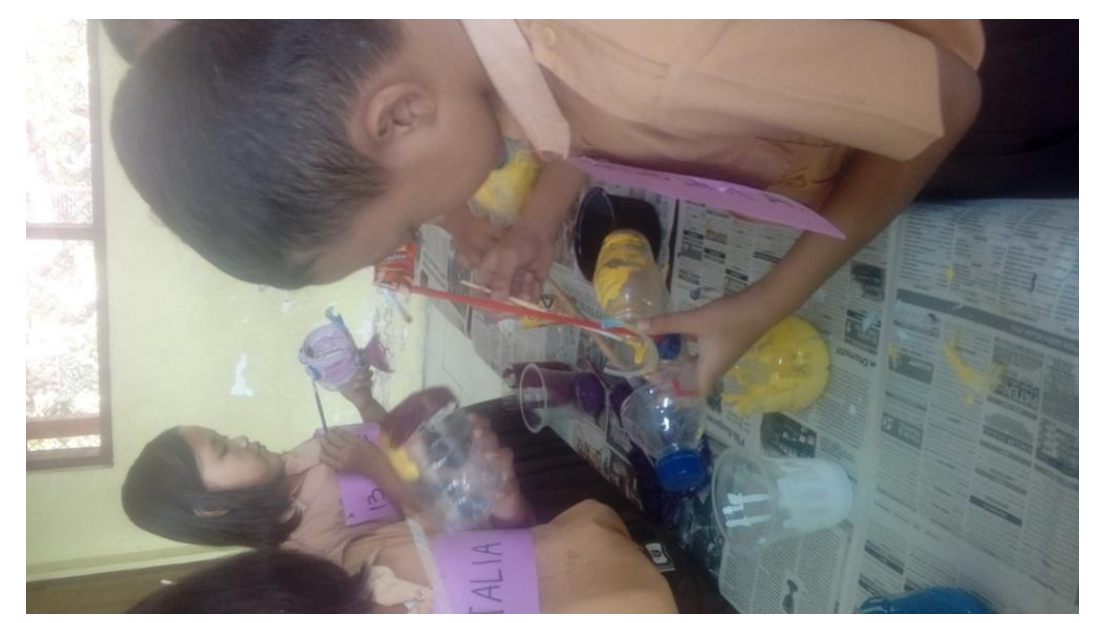

Gambar 3. Proses Pewarnaan Produk Kreatif

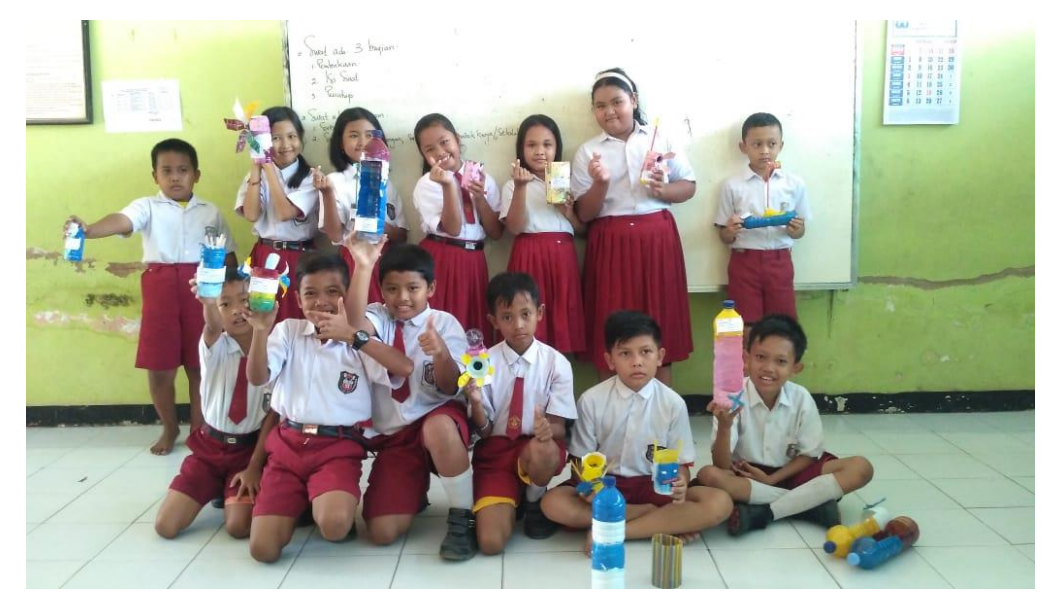

Gambar 4. Siswa dan Produk Kreatifnya

\section{PEMBAHASAN}

Berdasarkan hasil rekapitulasi diatas menyatakan bahwa kreativitas siwa dinyatakan sangat baik karena dari 14 siswa hanya 1 siswa yang memperoleh kategori "Baik" dan yang lainnya mendapatkan kategori "Sangat Baik". Prosentase yang diperoleh siswa beragam yang paling tertinggi dengan prosentase $94 \%$ dan yang terendah adalah $68 \%$.

Prosentase berturut-turut mulai dari yang paling tinggi higga paling rendah adalah 94\%, 94\%, 94\%, 87\%, 87\%, 87\%, 87\%, 87\%, 87\%, 87\%, 81\%, 81\%, 81\%, $68 \%$. Prosentase yang diperoleh berdasarkan 3 indikator yaitu kebaruan, pemecahan, dan keterperincian.

Skor indikator kebaruan dari 14 siswa untuk barang baru seluruh siswa mendapatkan nilai 4 karena mereka merasa bahan dasar yang dibuat merupakan barang 
baru karena sebelumnya belum pernah mengolah bahan tersebut menjadi bahan baru hal ini sesuai dengan teori Basemer dan Treffinger (dalam Munandar, 2009) bahwa jika dilihat melalui perkembangan anak, dan baginya karya itu merupakan karya baru dalam arti dia belum pernah membuat sebelumnya maka karya yang dihasilkan anak tersebut merupakan karya yang baru. Aspek keaslian dari 14 siswa secara berturut-turut memperoleh skor 4, 4, 4, 3, 3, 3, 3, 3, 3, 3, 3, 3, 2, 2. Bagi siswa yang menggunakan idenya sendiri dalam mengelola sampah plastik maka akan mendapatkan skor 4 memiliki skor 4 ini sesuai dengan teori Guilford (dalam Hidayat, 2012) yang menyatakan bahwa keaslian produk adalah kemampuan untuk menciptakan sesuatu yang baru dan asli sebagai hasil pemikiran sendiri.

Bagi siswa yang memiliki skor 3 dan 2 berarti ide yang mereka miliki muncul setelah mereka melihat apa yang ada di sekitar mereka mungkin melihat dari temannya, internet, dan di lingkungan sekitar mereka, yang membedakan skor 2 dan 3 adalah dalam pembuatannya yang mendapat skor 2 mereka meminta bantuan temannya untuk memotong bahan baku yang akan diolah. Hal ini senada dengan penelitian Cinthya dan Kusuma pada tahun 2018 (Cinthya \& Kusuma, 2018) yang menyatakan bahwa ide kreatif yang dihasilkan dapat muncul karena ada kegiatan untuk mengamati lingkungan fisik maupun sosial. Hal ini sesuai dengan teori Utami Munandar, 2009 ( Munandar, 2009) yang menyatakan bahwa kondisi yang memungkinkan seseorang menciptakan produk kreatif ialah dari pribadi sendiri maupun dari lingkungan sekitar.

Skor indikator pemecahan dengan aspek berguna dari 14 siswa secara berturutturut mencapatkan skor 4, 4, 4, 4, 4, 4, 3, 3, 3, 3, 3, 3, 2, 2. Siswa yang mendapatkan skor 4 adalah siswa yang menyebutkan 3 fungsi dari produk yang mereka buat, sedangkan yang mendapatkan skor 3 dapat menyebutkan 2 fungsi dari produk yang dibuat dan skor 2 hanya dapat menyebutkan 1 fungsi dari produk yang dibuat. Hal ini sesuai dengan penelitian Budiono, 2017 (Budiono, 2017) yang menyatakan bahwa memanfaatkan sampah plastik untuk diolah kembali menjadi suatu barang yang fungsinya berbeda dari sebelumnya. Astuti, 2015 juga menyatakan produk kreatif yang dihasilkan juga harus memiliki daya guna atau kebergunaan. Diperkuat dengan teori Basemer dan Treffinger (dalam Munandar, 2009) yang menyatakan bahwa produk yang dihasilkan harus memiliki nilai guna atau berguna.

Skor indikator keterperincian dengan aspek kompleks dari 14 siswa secara berturut-turut mendapatkan skor 4, 4, 4, 4, 4, 4, 3, 3, 3, 3, 3, 3, 3, 3. Siswa yang mendapat skor 4 berarti mereka mampu membuat detail produk secara lengkap antara lipatan, potongan dan warnanya, sedangkan yang mendapatkan skor 3 berarti mereka tidak membuat dari salah satu detail dari lipatan, potongan, dan warnanya. Hali ini sesuai dengan pernyataan Susanto, 2013 (dalam Yunia Mandasari dan Nadjamuddin, 2015) yang menyatakan bahwa komposisi warna dan bentuk tekstur harus serasi. 
Diperkuat dengan teori Basemer dan Treffinger (dalam Munandar, 2009) yang menyatakan bahwa produk yang dihasilkan merujuk pada derajat sejauh mana produk itu menggabungkan unsur -unsur yang tidak sama/serupa menjadi keseluruhan yang kompleks. Aspek yang diambil dalam penelitian ini adalah kompleks dimana produk yang dihasilkan harus memenuhi lipatan, potongan dan warnanya.

Menurut Basemer dan Treffinger (dalam Munandar, 2009) produk tidak perlu menonjol dalam semua kriteria. Misalnya nilai cukup baik pada semua kriteria sebanding dengan nilai sangat baik pada beberapa kriteria, dan rendah pada beberapa lainnya.

\section{Simpulan}

Kreativitas siswa kelas 3 dalam mengelola sampah plastik di SD Negeri 1 Wonokromo Kecamatan Gondang rata-rata dari 14 siswa yang memiliki tingkat kreativitas sangat tinggi adalah 13 siswa dan 1 siswa memiliki kreativitas baik Di kelas 3 ini siswa sudah dapat mengelola sampah plastik dengan beragam bentuk produk dari sampah plastik. Dibandingkan dengan observasi awal yang hasil karya siswanya hanya memanfaatkan 1 jenis sampah plastik dengan hasil akhir (produk baru) yang sama setiap siswa.

\section{Daftar Rujukan}

Budiono. (2017). Pemanfaatan Limbah Botol Plastik Menjadi Prakarya Boneka Pinguinsebagai Bentuk Implementasi Dari Pendidikan Lingkungan Hidup, 2(2).

Cinthya, A., \& Kusuma, H. B. (2018). Botol Plastik Bekas, 2(1), 10-16.

Hidayat. (2012). Berpikir Kreatif (Penghayatan dan Latihan Menggugah Motivasi Kreatif). Bandung : Mitra Sarana.

Moleong, Lexy J. (2017). Metodelogi Penelitian Kualitatif Edisi Revisi. Bandung: PT Remaja Rosda Karya.

Munandar, Utami. (2009). Pengembangan Kreativitas Anak Berbakat. Jakarta : Rineka Cipta

Sudarma, Momon. (2013). Mengembangkan Keterampilan berpikir Kreatif. Depok: PT Raja Grafindo Persada

Sudijono, Anas. (2009). Pengantar Evaluasi Pendidikan. Jakarta : Raja Grafindo Persada

Sugiyono. (2016). Metode Penelitian Pendidikan Pendekatan Kualitatif, Kuantitatif, dan $R \& D$. Bandung : Alfabeta

Yunia Mandasari dan Nadjamuddin. (2015). Kata Kuci : Pendidikan Dasar, 1, 1-21. 